\title{
Update on the prevalence of allergic sensitization to Russian thistle in South-eastern Ontario: retrospective chart review
}

\author{
Nina Lakhani ${ }^{* *}$, Anne K Ellis ${ }^{1,2}$ \\ From Canadian Society of Allergy and Clinical Immunology Annual Scientific Meeting 2011 \\ Quebec, Canada. 20-23 October 2011
}

\section{Background}

Russian thistle (RT) was identified as a potentially clinically significant allergen in phase three of the NHANES survey with over $15 \%$ of tested individuals having positive skin tests. Previously estimated prevalence rates of RT skin positivity in Kingston and surrounding catchment area were $\sim 10 \%$. RT was subsequently added to a standard allergen skin testing panel at Queen's University's Allergy clinic.

\section{Objective}

To determine the updated prevalence rate of skin test positivity to Russian Thistle in patients from Kingston and the Southeastern Ontario area, in an unselected patient population.

\section{Methods}

A retrospective chart review documented the rate of sensitization to RT extract (ALK-Abello). Only patients with appropriate histamine responses were included. Demographic data, presence of relevant clinical symptoms and skin test responses to RT and other crossreacting allergens were recorded.

\section{Results}

609 charts were reviewed and 304 patients underwent skin testing for RT. Of these, 43 (13.8\%) were positive. Of the test-positive cohort, $86 \%$ (37/43) had concomitant symptoms of allergic rhinitis/asthma. $41 \%$ (18/43) had symptoms that correlated with the predominant RT pollen season. $93 \%$ and $58 \%$ of these persons had concomitant positive skin tests to ragweed and birch; allergens with known cross-reactivity.

\section{Conclusions}

This suggests the prevalence of skin test positivity to Russian thistle in Kingston and surrounding area to be approximately $14 \%$, with over $40 \%$ of patients reporting correlating symptoms. A higher degree of cross-reactivity with ragweed than previously known may exist. Continuing to include Russian thistle as part of routine allergen testing may further establish its clinical significance.

\section{Author details}

${ }^{1}$ Department of Medicine, Queen's University, Kingston, ON, Canada. ${ }^{2}$ Department of Biomedical and Molecular Sciences, Queen's University, Kingston, ON Canada.

Published: 14 November 2011

doi:10.1186/1710-1492-7-S2-A19

Cite this article as: Lakhani and Ellis: Update on the prevalence of allergic sensitization to Russian thistle in South-eastern Ontario: retrospective chart review. Allergy, Asthma \& Clinical Immunology 20117 (Suppl 2):A19. 